Mini Review

\title{
Nuclear receptors - target molecules for isoflavones in cancer chemoprevention
}

\author{
Lucia Bialešová ${ }^{1}$, Július Brtkoํ․ Vladimír Lenko ${ }^{1,2}$ and Dana Macejová ${ }^{1}$ \\ ${ }^{1}$ Laboratory of Molecular Endocrinology, Institute of Experimental Endocrinology, Slovak Academy of Sciences, Bratislava, \\ Slovak Republic \\ ${ }^{2}$ Department of Urology, University Hospital Bratislava - St. Cyril and Method Hospital, Bratislava, Slovak Republic
}

\begin{abstract}
Breast cancer is the most occurring type of cancer among women. In Slovakia, there are yearly diagnosed about 1900 new cases of this disease. Breast cancer treatment is very expensive, psychic stressful and in some cases ineffective. Therefore, it is essential to search for new and/or alternative methods for breast cancer treatment, since nuclear receptors are considered to be a central goal for maximizing treatment opportunities in breast cancer. Among natural ligands for estrogen receptors (ER $\alpha$ and $E R \beta)$, which are member of nuclear receptors superfamily, belongs also isoflavones. These natural compounds have similar structure to main female hormon-17 $\beta$ estradiol. A rich source of isoflavones is soy and its products. Three aglycones form of isoflavones (genistein, daidzein, glycitein) are predominantly found in soybean and red clover. Among other important isoflavones belongs also biochanin $\mathrm{A}$ and formononetin.
\end{abstract}

Key words: Isoflavones - Nuclear receptors - Breast cancer - Chemoprevention

Abbreviations: AhR, aryl hydrocarbon receptor; ARNT, nuclear receptor translocator; CYP450, cytochrome P450; DD, D-Dimer; ER, estrogen receptor; 8HD, 8-hydroxydaidzein; MCF-7, human breast cancer cell line ER positive; MDA-MB-231, human breast cancer cell line ER negative; MMP, matrix metalloproteinase; NF- $\mathrm{kB}$, nuclear factor kappa-B; O-DMA, O-desmethylangolensin; ROS, reactive oxygen species; VEGF, vascular endothelial growth factor.

\section{Introduction}

Nuclear receptors (NRs) are important transcriptional factors essential for a broad aspect of human physiology, ranging from development and differentiation to metabolic homeostasis (Jin and Li 2010). In 1990, only 15 members of the steroid/thyroid/retinoid receptor superfamily had been identified as nuclear receptors for all the known fatsoluble hormones. Five years later, more than 150 members of nuclear family with a large diversity of animal species from worm, to insect, and to human have been identified (Mangelsdorf 1995). Nowadays, it is known that the human genome contains $48 \mathrm{NRs}$ (Jin and Li 2010), and they are di-

Correspondence to: Dana Macejová, Laboratory of Molecular Endocrinology, Institute of Experimental Endocrinology, Slovak Academy of Sciences, Bratislava, Slovak Republic

E-mail: ueenmace@savba.sk vided into three groups. The first group comprises a family of steroid hormones receptors, which includes glucocorticoid receptor (GR), estrogen receptor (ER), androgen receptor (AR), mineralocorticoid receptor (MR), and receptor for progesteron (PR) (Pearce and Jordan 2004). The second group involves nuclear receptors for all-trans retinoic acid (RARs), 9-cis retinoic acid (RXRs), vitamin $\mathrm{D}_{3}$ receptor (VDR), and thyroid receptors (TRs) (Nikolenko and Krasnov 2007). RARs have the ability bind both all-trans retinoic acid and 9-cis retinoic acid with similar affinities, while RXRs bind predominantly 9-cis retinoic acid (Brtko and Dvořák 2011). Retinoids have really an irreplaceable role in the human organism. Their presence is indispensable in many functions important for life, as growth, reproduction, normal function of vision, they are factors modulating growth and differentiation of cells, and have antitumour activity (Brtko 2007). The numbers of nuclear receptors have been revealed by sequence similarity to existing nuclear receptors but their ligands still 
remain unidentified. These receptors belong to the third group named as "orphan receptors" (Nikolenko and Krasnov 2007). The group of orphan nuclear receptors is a topic of enormous interest in pathophysiology, since the discovery of their cognate ligands should lead to the discovery of new chemical preparations exploitable in the treatment of civilization diseases (Jin and Li 2010). Among the nuclear receptors that heterodimerize with the RXRs, similarly as TRs, RARs and VDR, belong liver X receptor (LXR), farnesoid $\mathrm{X}$ receptor (FXR), and also the peroxisome proliferator-activated receptors (PPARs) (Pearce et al. 2004).

ERs, members of the nuclear receptor superfamily, play a crucial role in mammary gland growth, differentiation, and also are responsible in inception and development of about $70 \%$ breast cancer. Estrogens act through two types of nuclear receptors: estrogen receptor alpha (ER $\alpha)$ and estrogen receptor beta $(\mathrm{ER} \beta)$. Estrogen receptors are liganddependent transcription factors that mediate the biological effects of estrogens and antiestrogens (Platet et al. 2004). These receptors have been found in both extranuclear and intranuclear space of the cell (Lee et al. 2005). Both types of receptors are products of separate genes located on different chromosomes. ERa is located on locus 6q25.1 and ER $\beta$ occurs on locus 14q23-24.1. ER $\alpha$ and ER $\beta$ comprise eight exons separated by seven intronic regions and they have more than 140 kilobases (ESR1) and approximately 40 kilobases (ESR2) (Ascenzi et al. 2006).

Comparison of ERa cDNA sequence from human with those of chicken, rat, and mouse shows a high level of conservation between different species with the exception of the 5 '-end. ER $\beta$ is smaller molecule than ER $\alpha$ but it possesses a similar structure and considerable homology in both the DNA binding domain (DBD) and the ligand binding domain (LBD) (Ascenzi et al. 2006). ERa is expressed in various tissues and organs, predominantly in the uterus and in the liver, as well. ER $\beta$ has been found to be expressed in bone, cardiovascular system, and in the brain (Lee et al. 2005), ER $\beta$ is also well expressed in the testis, immune system, urogenital system, as well as in central nervous system, lung, mammary gland, kidney, intestinal tract in particular colon (Gustafsson 2000). Generally, the percentage of ERa positive cells is about $10-20 \%$ in healthy mammary gland. The ratio is increased in proliferative benign disease, particularly when associated with atypia, and in low-grade ductal carcinoma in situ (DCIS). ERa is found in 50-80\% of breast tumours and ERa status is essential in making decisions for endocrine therapy (Platet et al. 2004). About $60-70 \%$ of epithelial cells in rats, expresses ER $\beta$ at all stages of breast development. Both types of receptors are expressed up to $60 \%$ in epithelial cells during lactation, but this is extraordinary during pregnancy. Moreover about $90 \%$ cells, which express ER $\beta$, usually do not proliferate. Thus, ER $\beta$ can be considered an important modulator of proliferation and invasion of breast cancer cells. The loss of ER $\beta$ expression could be one of the events leading to the development of breast cancer (Lazennec et al. 2001). The ERs seems to be an important target for drugs development and breast cancer treatment. The interaction of estrogens with ERs can lead to increasing proliferation of target cells. That knowledge is advantageously exploited in endocrine therapy of patients, which is based on disruption of the interaction of estrogen with the ERs. This target can be achieved by blocking the production of estrogen by ovariectomy, inhibiting the conversion of estrogen precursors using aromatase inhibitors (Pearce and Jordan 2004). Activated ERs mostly bind to the target promoter sequence as a homodimer, but it has also been shown that ER $\alpha$ and ER $\beta$ can dimerize, as well. To the discovery of ERs genes contributed also the observations showing that sheep fed on the red clover suffered to reproductive dysfunction. In these sheep, both estrogen and progesteron levels were disrupted in blood circulation. Later, these observations were explained as a result of estrogenic activity of isoflavones in the clover (Ricketts et al. 2005). ER $\alpha$ and ER $\beta$ share common structural domains (Pearce and Jordan 2004), but they are not identical in the transcriptional activities of certain ligands, cell types, and promoter contexts (Im et al. 2008). The DNA-binding domain is the most highly conserved region between ERa and $\mathrm{ER} \beta$, with $96 \%$ identity. This allows both receptors to bind to similar target sites. Between ER $\alpha$ and ER $\beta$ exists 53\% sequence identity (Pearce and Jordan 2004). ERs can be positively or negatively regulated by transcriptional regulators such as histone deacetylases (HDACs) and histone acetyltransferases (HATs) (Im et al. 2008).

\section{Breast cancer}

Cancer is disorder widespread in whole world, and breast cancer ranks among the most frequent cancer in women. In Slovakia, 1900 new cases of this disease are diagnosed yearly. The number of younger women with this type of cancer is still increasing among affected women during the last years. In the past, breast cancer occurred in women aged 60-65 years, however, during the last two decades, the age limit for breast cancer decreased to 25-45 years (Bella and Kállayová 2011). In Slovakia, breast cancer represents $18 \%$ from all malignances in women. In 2006, the National Cancer Registry registered even 2264 new cases of this malignant disease, and the number of deaths was 708 (Bella and Kállayová 2011). In Czech Republic are diagnosed almost 5000 new cases of breast cancer yearly. In Europe, breast cancer affects 6-7\% women population and in the USA it ranges from $25 \%$ to 30\% (Ondrušová 2009).

In general, cancer is a very complex process conditioned by uncontrolled cell proliferation, morphologic and cell transformation, angiogenesis, apoptosis deregulation, increasing 
invasive activity and the development of local and distant metastases (Suva et al. 2009). Breast cancer treatment, as the other cancer treatments, is very expensive, psychic stressful and in some cases ineffective. From these reasons search for new and/or alternative methods of breast cancer treatment is highly required. Breast cancer is type of cancer disease, which is predominantly diagnosed in women living in industrialised countries, and it represents up to one third of all cancers. The number of elderly women with diagnosed breast cancer is still increasing (Mustacchi et al. 2007). Breast cancer is characterized i) according to clinical manifestation, based on expression of tumour markers and by histological manifestation. The two most common type of invasive breast cancer are ductal and lobular carcinomas. Additional types of breast cancer include mucinous, tubular, comedo, inflammatory, medullary, and papillary carcinomas but these types are rather rare ( $\mathrm{Li}$ et al. 2005); ii) according to the form, i.e., sporadic, familiar, and hereditary breast cancer (Bella 2009), and iii) according to hormonal sensitivity, human breast cancer can be divided to hormone-dependent and hormone-independent subtypes. Estrogen is the most important hormone for women, which takes part in the development and growth of hormone-dependent type of breast cancer (Mu et al. 2009). Mammary glands can synthesise estrogens from circulating precursors and there is increasing evidence that phytoestrogens can inhibit estradiol synthesis. It can be one of the protective mechanisms in fight against developing this type of cancer (Rice and Whitehead 2008). Majority of breast tumours expresses estrogen receptors, and thus estrogen's negative role originates from its support of tumour growth. As it has been mentioned previously, the incidence of breast cancer increases with age, despite the loss of ovarian hormones in postmenopausal women. This paradox can be explained by the fact that in extragonadal organs e.g. breast, brain, muscles, skin, bones, adipose tissue, the synthesis of androgens and estrogens originate from their inactive precursors of adrenal gland cortex but in lower quantity than that of ovary. After menopause, the most of estrogens is produced by peripheral tissues. Enzymes present in breast tissue convert inactive circulating precursors, such as androstenedione, dehydroepiandrostenedione (DHEA), its sulfated form DHEA-S, and estrone sulfate (E1S) into biologically active androgens and estrogens (Rice and Whitehead 2006).

\section{Estrogens and phytoestrogens}

Estrogens, like other steroid hormones, are natural substances of cyclopenthanophenanthrene origin, the synthesis of which starts from cholesterol (Ascenzi et al. 2006). In humans, several estrogen-related compounds are present. The most potent and dominant estrogen of human body is $17 \beta$-estradiol; estrone and estriol play an important role, as well. Estrogens are synthetized predominantly in ovaries of premenopausal women. Among other organs, which can synthetizes estrogens through testosterone aromatization are brain and adipose tissue. Men can also synthetized estrogens but in lower concentration when compared to women. In men peripheral blood circulate $69 \mathrm{pg} / \mathrm{ml}$ estrogen on average, and in non-ovulating women $199 \mathrm{pg} / \mathrm{ml}$. In addition to endogenous sources, estrogens level can be increased by the treatment with $17 \alpha$-ethinyl estradiol (used as oral contraceptive), mestranol, premarin (used in the hormone replacement therapy), and diethylstilbestrol (used in the treatment of advanced stage breast and prostate cancers). From a physiological point of view, estrogens are essential for growth and maintenance functions of the various reproductive and non-reproductive organs (Okoh et al. 2011). Estrogens also play an important role in bone development and bone density, and they have a crucial role in maintaining cardiovascular system; moreover they are taking part in regulating mood and are closely involved in the creation, maintenance and reparation of nerve connections (HilakiviClarke et al. 2002). Effects of estrogen in target tissues are widely determined by metabolic pathways of conjugation and catabolism. In postmenopausal women, more than $80 \%$ of circulating endogenous estrogens is in inactive form as conjugates of glucuronide or sulfate (Wood et al. 2007).

The fact that incidence of breast cancer in Japanese women is lower than in American or European women is well known. When Japanese people migrated to the United States, the next generation of women had the same incidence of mammary cancer than aboriginal women. It is indicating that environment is responsible for development of breast cancer more than breed. The biggest difference in lifestyle of Japanese women in comparison with American women is in diet, predominantly in protein intake. In comparison with Japanese people that consume predominantly proteins from soy products, Americans consume much more proteins from meat (Wuttke et al.2007). Soy and soy products are the one of the main food in many Asian countries like in Japan, China, Korea, and Indonesia (Adlercreutz 2003). Concerning soy and soy food products, there is a great interest for this staff because they can be useful in prevention and/or treatment of cardiovascular disorders, chronic diseases, osteoporosis and cancer. Potential benefits of soy and soy products are attributed to isoflavones, a subclass of flavonoids that possesses numerous biological properties and are most commonly found in legumes (Andres et al. 2009). Soy contains many phytochemicals including isoflavones, phytic acid, trypsin inhibitors and saponins (Lee et al. 2005), phytosterols, protease inhibitors, inositol hexaphosphates, sphingolipids, phenolic acids. Isoflavones content is $1.2-2.4 \mathrm{mg} / 1 \mathrm{~g}$ soybeans. This variability of isoflavones is due to genotypes, environment, location of growth, post-harvest storage, and assay procedures (Luthria et al. 2007), plant parts, freshness, cultivars, 
harvesting seasons, and country of origin (This et al. 2011). The same parameters can influence the content of isoflavones in fruit, vegetables, and in herbs as well (Luthria et al. 2007). The phytoestrogens are natural compounds found in plants, with a weak estrogenic activity that can bind to estrogen receptors and initiate estrogen-dependent transcription (Rise and Whitehead 2008). Phytoestrogens are also considered to be important antioxidants. Phytoestrogens disrupt the action of DNA topoisomerase II and ribosomal S6 kinase which could explain their observed effects on differentiation, proliferation, and cells apoptosis (Liggins et al. 2000). There are many favorable effects of phytoestrogens on breast cancer cells. They could be involved in inhibition in tyrosine or other protein kinases, change growth factor action, inhibit angiogenesis, cause inhibition of $3 \beta$-hydroxysteroid dehydrogenase, $17 \beta$-hydroxysteroid dehydrogenase type 1, 5a-reductase, phenol sulfatase, topoisomerase I and II, and aromatase (Adlercreutz 2003). There is evidence that phytoestrogens could have a protective effect on the initiation or progression of breast cancer by inhibiting the local production of estrogens from circulating precursors in breast tissue. They can inhibit action of enzymes, which are capable to synthesize estrogens from circulating androgens and estrogen sulfate (Rise and Whitehead 2006). Another mechanism by which isoflavones may reduce the risk of breast cancer is explained by their ability affect on endogenous levels of SHBG (Sex Hormone Binding Protein) and on the menstrual period. From several in vitro and in vivo data, it is suggested that phytoestrogens stimulate SHBG production in liver cells and they reduce endogenous levels of sex hormones and extent menstrual period (Adlercreutz 2003). Phytoestrogens are present mainly in soybeans; lignans are present also in fruits, cereals, rye, and linseed. In a lesser extent are available information on flavones and coumestrans (Rice and Whitehead 2003; Magee et al. 2004).

\section{Isoflavones}

Isoflavones are a class of phytoestrogens, plant-derived compounds with estrogenic activity. They are heterocycles comprising the oxygen atom, the molecule containing a 3phenylchroman skeleton hydroxylated at 4 ' and 7 positions. Based on the substitution pattern on carbon 5 and 6, three aglycones form of isoflavones are predominantly found in soy beans (Luthria et al. 2007), i.e. genistein (50\%), daidzein (40\%), and glycitein (10\%) (Kang et al. 2010). These three major isoflavones can also exist in conjugated forms with glucose (daidzin, genistin, glycitin), malonylglucose (malonyldaidzin, malonylgenistin, malonylglycitin), and acetylglucose (acetyldaidzin, acetylgenistin, acetylglycitin) (Luthria et al. 2007). Glucosidic conjugates of isoflavones have different binding affinities to ERs based on their structure and ER subtypes (Lee et al. 2005). The chemical structure of soy isoflavones is very similar to estrogen molecules, suggesting their weak estrogenic activity (Hillman and Singh-Gupta 2011). The main mechanism of isoflavones action results from their ability to interact with ERs (Matsumura et al. 2005). But their affinities for the ER are at least ranging from 1000 to 10000 times lower than that of estradiol (Rice and Whitehead 2006). Phytoestrogenes may interfere with the effects of endogenous estradiol levels either as agonists, in the case of reduced concentration of plasma estradiol levels, or as an antagonists, when the endogenous levels of estrogen are increased (Matsumura et al. 2005). The glycoside conjugates of isoflavones are biologically inactive before hydrolysis. They remain unmodified during various food preparations. After ingestion the glycosides they are hydrolyzed to free aglycones which are subjected to metabolic processes, such as demethylation and reduction, by gut microflora. Aglycones and their metabolites are absorbed and transported to the liver, where liver microsomes catalyze the hydroxylation and conjugation of isoflavones to more hydrophilic metabolites, sulfonic or glucuronic acid conjugates which are excreted by urine. Only a small part of the absorbed isoflavones enters into enterohepatic circulation (Heinonen et al. 2003).

Research studies have shown that the inhibition of human cancer cell growth by soy isoflavones is linked with the modulation of genes, which are involved in the cell cycle and apoptosis. Clinical trials have shown that isoflavones are nontoxic and safe compounds for human beings in contrast to chemotherapeutic drugs, but they have still limited activity as pharmaceutical preparations for cancer therapy (Hillman and Singh-Gupta 2011). The question of safe use of phytoestrogen, especially isoflavones supplements for women at high risk of breast cancer, has been discussed. Experiments on MCF-7 cell line showed increasing cell proliferation after isoflavones treatment, but the same effects when performing in vivo experiments have been challenged. Recent studies revealed anti-cancer effects of isoflavones through inhibition of angiogenesis and migration of metastases (Imhof et al. 2008). Satih and his group, when using pangenomic microarray techniques, have shown that isoflavones genistein and daidzein differently modulate a variety of pathways, which takes place in the process of carcinogenesis, apoptosis, cell communication, xenobiotic and lipid metabolism, as well as signal transduction. In addition, these pathways affect tumour status in breast cell lines; thereby there is a piece of evidence for the hypothesis that soy isoflavones could have a chemopreventive effect during the first-initiation phase of tumour development (Satih et al. 2010). When both subtypes of ERs are present, isoflavones act preferentially through ER $\beta$ (Imhof et al. 2008).

New investigations confirm that isoflavones are suitable ligands for ERs. The structure of isoflavones is very similar to estradiol and thus isoflavones possess a weak estrogenic 
activity, as well. Isoflavones bind to the ERs, which inhibit binding of natural hormone estradiol, and thus may attenuate proliferative influence of estradiol to breast tissue. These substances occurring predominantly in soy and soy products and red clover belong to the group of phytoestrogens, and thus soy and red clover represent the main source of isoflavones in the nature. Isoflavones have got to the center of scientific interest for many laboratories over the world due to the fact that the countries with high intake of soy products in the diet as China and Japan are known for decreased incidence of breast cancer. Table 1 represents the names, structure and formulas of the most studied isoflavones.

Aryl hydrocarbon receptor (AhR) is a member of the basic helix-loop-helix (bHLH) Per-ARNT-Sim (Pas) family and also shares basic signs of the nuclear receptor action (Medjakovic 2010). Among other members of this family belongs nuclear receptor translocator (ARNT) (Callero and Loaiza-Pérez 2011). Many reports bring evidence about crosstalk between nuclear receptors and AhR (Kharat and
Saatcioglu 1996; Safe et al.1998). A lot of naturally plant substances act as AhR ligands, including isoflavones. These compounds have been reported as agonists and also as antagonists of $\mathrm{AhR}$. Isoflavones inhibit the enzyme activity of CYP1A1 due to their action at non-transcriptional level. The CYP1A1-modulating effects of isoflavones depend on cell types, and on action with other enzymes of xenobiotic pathways. While non-tumour-derived cells express CYP1A1 mRNA levels, ERa-positive tumour cells express high levels of CYP1A1. On the other hand, CYP1A1 mRNA expression in ER-negative tumour cells is minimal (Medjakovic 2010). AhR ligands have the capacity to bind to ERs and they can modulate ERs signalling pathways in breast cancer cells. Estrogen can be then metabolised by AhR-driven genes such as CYP1B1 to toxic metabolites that act as genotoxines. This piece of evidence strengthens the theory on interaction between AhR and ER signalling pathway involving isoflavone mechanism of action (Callero and Loaiza-Pérez 2011). Metabolic pathway of isoflavone is shown in Figure 1.

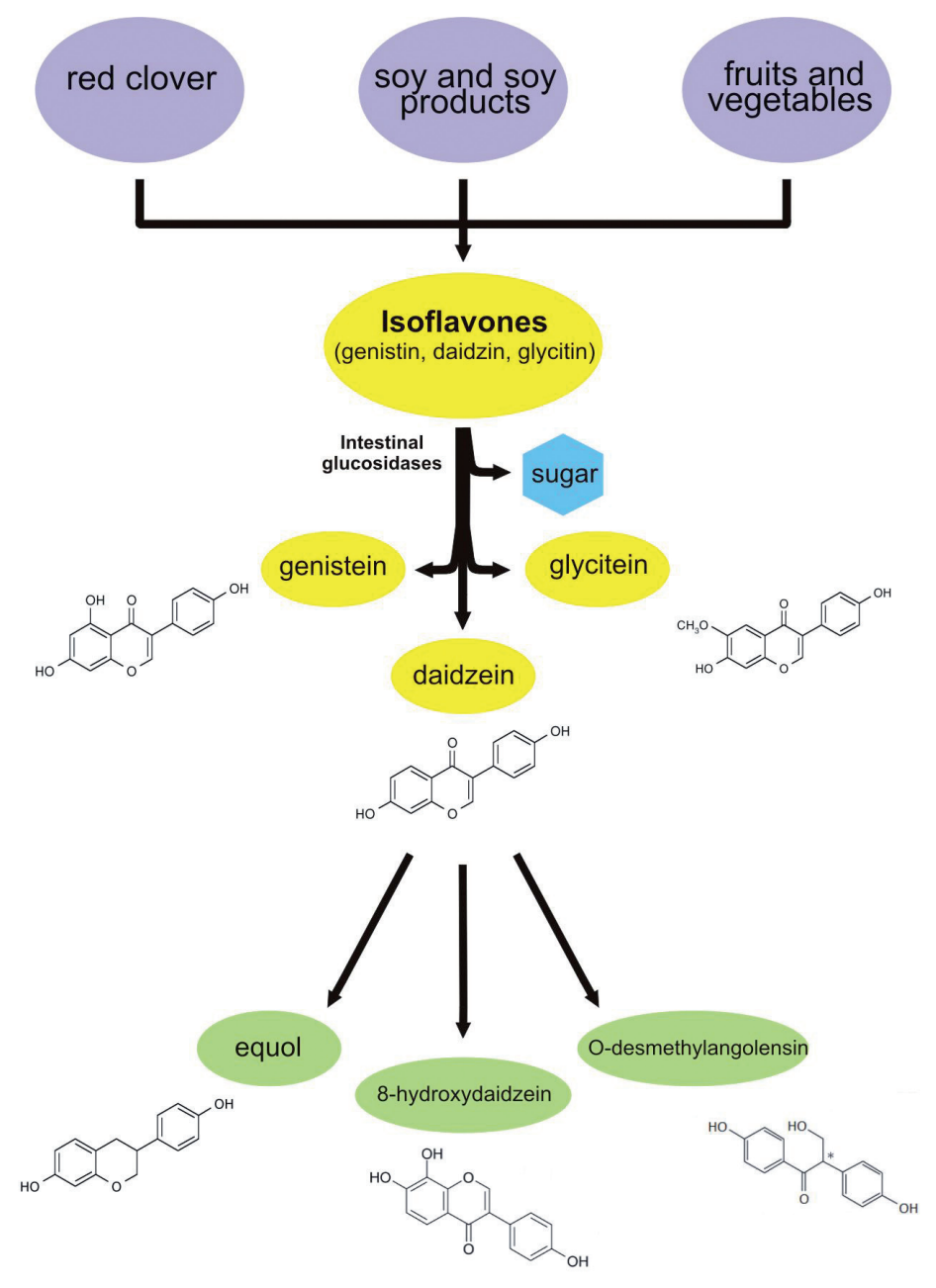

Figure 1. Metabolic pathway of isoflavones. In plants and several foodstuffs (red clover, soybeans, fruit and vegetables) isoflavones are present as glycosides - genistin, daidzin, glycitin. After consumption, of isoflavones, they are hydrolyzed by intestinal glucosidases, which releases the aglycones - genistein, daidzein, and glycitein. Isoflavon daidzein can be metabolized in a part of human population by gut microflora to another isoflavones as equol, 8- hydroxydaidzein and O-desmethylangolensin. 
Table 1. Names, structures and formulas of selected the most studied isoflavones and estradiol

\begin{tabular}{|c|c|c|c|}
\hline Name & & Structure & $\begin{array}{c}\text { Molecular } \\
\text { formula }\end{array}$ \\
\hline Genistein & $\begin{array}{l}\text { (5,7-Dihydroxy-3-(4-hydroxy- } \\
\text { phenyl)chromen-4-one) }\end{array}$ & & $\mathrm{C}_{15} \mathrm{H}_{10} \mathrm{O}_{5}$ \\
\hline Daidzein & $\begin{array}{l}\text { (7-Hydroxy-3-(4-hydroxyphe- } \\
\text { nyl) chromen-4-one) }\end{array}$ & & $\mathrm{C}_{15} \mathrm{H}_{10} \mathrm{O}_{4}$ \\
\hline Equol & $\begin{array}{l}\text { ((3S)-3-(4-Hydroxyphenyl)-7-c } \\
\text { hromanol) }\end{array}$ & & $\mathrm{C}_{15} \mathrm{H}_{14} 0_{3}$ \\
\hline Biochanin A & $\begin{array}{l}\text { (5,7-dihydroxy-3-(4-methoxy- } \\
\text { phenyl)chromen-4-one) }\end{array}$ & & $\mathrm{C}_{16} \mathrm{H}_{12} \mathrm{O}_{5}$ \\
\hline Formononetine & $\begin{array}{l}\text { (7-hydroxy-3-(4-methoxyfenyl) } \\
\text {-4-benzopyron) }\end{array}$ & & $\mathrm{C}_{16} \mathrm{H}_{12} \mathrm{O}_{4}$ \\
\hline Estradiol & $\begin{array}{l}((17 \beta) \text {-estra-1,3,5(10)-triene- } \\
3,17 \text {-diol) }\end{array}$ & & $\mathrm{C}_{18} \mathrm{H}_{24} \mathrm{O}_{2}$ \\
\hline
\end{tabular}

\section{Genistein}

Genistein (4', 5, 7-trihydroxyisoflavone) is a phytoestrogen that occurs in high doses in soy products. It is a member of isoflavones branch of the flavonoid family, which contain more than 5000 compounds. First time it was isolated in 1899 (Messina and Wu 2009; Pavese et al. 2010). Genistein has many biological effects but the most important is its ability to inhibit metastatic activity mammary, prostate, colon, and other types of tumours (Pavese et al. 2010). Animal studies have shown that animals when treated with high doses of genistein in their diet have decreased incidence of mammary tumours. Thus, it has been suggested that isoflavones rich diets can reduce the susceptibility of rats to mammary cancer (Davis et al. 2008). The great interest on genistein as a potential therapeutic agent for breast cancer treatment resulted from the findings based on the fact that consumption of genistein reduces the risk of mortality in several types of cancers (Pavese et al. 2010). Genistein acts as a potential tyrosinkinase (Liggins et al. 2000) and DNA topoisomerase inhibitor; it is involved in antioxidant and cell cycle activitities. In human epidermal carcinoma cells, genistein blocks EGF-mediated tyrosine phosphorylation (Dixon and Ferreira 2002). Genistein stimulates a number of antioxidative enzymes, such as superoxiddismutase, reductase, glutationperoxidase, and catalase, and it induces cell differentiation in tumours. Genistein down-regulates epidermal growth factor and ErbB2/Neu receptors in cancer cells and it may also inhibit cell invasion by inhibiting matrix metalloproteinase 9 (MMP-9) and upregulating MMP-9 and TIMP1 (tissue inhibitor of metalloproteinases) and some other 
trypsin inhibitors. Some data suggest that for genistein action, TGF $\beta$-1 signalling pathways might be important, as well (Adlercreutz 2003). Genistein possesses structural similarity with the potent human estrogen $17 \beta$ estradiol, particularly in phenolic ring structure and the distance between its $4^{\prime}$ - and 7-hydroxyl groups. Other structural similarities have also been noted between genistein and tamoxifen, which is synthetic antiestrogen used as chemopreventive agent in women with high risk of breast cancer (Dixon and Ferreira 2002). It has been found that genistein, in comparison with its other derivates, exerts higher affinity to ER $\beta(8.4 \mathrm{nM})$ than to ERa (145 nM) (Lee et al. 2005; McCarty 2006). Many studies have shown that NF- $\mathrm{kB}$ is an important target of genistein action in cancer cells (Hillman and Singh-Gupta 2011). The transcription factor NF- $\mathrm{kB}$ is a major signalling molecule, which is involved in many physiological processes, e.g., control of cell growth, apoptosis, inflammation, stress response, etc. It is also involved in an immune response and in adaptive responses to changes in cellular redox balance (Shukla et al. 2004). Genistein inactivate Akt/NF- $\mathrm{kB}$ pathway in prostate cancer cells. $\mathrm{NF}-\kappa \mathrm{B}$ is constitutively activated in prostate cancer and other cancers and correlates with progression of tumours. Ionizing radiation activatesNF- $\mathrm{kB}$ as an immediate response to protect cells from apoptosis, a mechanism that could be implicated in cell survival and radiorezistance. Besides the radiation, genistein or other isoflavones can inhibit NF-kBDNA-binding activity by blocking the translocation of NF- $\mathrm{kB}$ subunits to the nucleus, thereby inhibiting the transcription of target genes, which are incorporated in the regulation of cell cycle and proliferation in prostate cancer cells (Hillman and SinghGupta 2011). Furthermore, genistein can inhibit invasion of the highly metastatic, estrogen receptor negative breast cancer cell line MDA-MB-231 in vitro. This finding is associated with down-regulation of MMP-9 (Magee et al. 2004). Genistein also regulates the expression of apoptotic genes, and induces apoptosis through a p53-independent pathway. It has also been shown that genistein is a potent inhibitor of growth in estrogen receptor negative MDA-MB-468 cells. This might suggest that isoflavones can act via ER-independent pathways. Genistein also inhibits mammalian DNA topoisomerase II in mouse leukemia cells L-1210 (Davis et al. 2008), inhibits angiogenesis and has also genotoxic effects (Magee et al. 2004). Trifiletti et al. (2008) have found that although genistein has only a similar structure when compared to estradiol, it binds to ERs and can act as a selective estrogen receptor modulator, but its procoagulant effects are rather different of estrogen. Genistein is incapable to modify prothrombin levels $(\mathrm{F} 1+2)$, but it significantly reduces $\mathrm{D}$-dimer levels (DD). This is considered very interesting, because the DD levels are independently associated with the incidence of coronary events in postmenopausal women. The conclusion of Triffileti's group work was to claim that genistein is capable not only to inactivate hemostatic system, but it reduces DD levels, which can positively affect the hemostatic system. These results pointed out to cardioprotective function of genistein (Trifiletti et al. 2008). Studies have shown biphasic effect of genistein on the growth MCF-7 cell line. MCF-7 is an estrogen receptor positive cancer cell line, which expresses predominantly ERa (Imhof et al. 2008). It has also been shown that genistein exerts a biphasic effect on the cell growth in MCF-7 cell line. Low concentration stimulates cell growth and enhances expression of pS2 gene, and on the other hand, high concentrations of genistein (above $10 \mu \mathrm{M}$ ) inhibit cell growth by blocking the cell cycle at the G2-M phase. Antiestrogens can inhibit proliferative action of genistein at low concentrations. This indicates that an estrogen receptor-mediated mechanism is involved in the mode of action. However, the inhibition of cell growth at high concentrations of genistein is not prevented by estrogen or antiestrogen, suggesting that this mechanism is not mediated through ER, but it may be due to other mechanisms involving inhibition of tyrosine phosphorylation (Matsumura et al. 2005). In the recent study Li et al. (2013) showed changes in the expression and epigenetic modulations of several key tumour-related genes, e.g., tumour suppressor genes, p21WAF1 (p21) and p16INK4a (p16), and tumour promoting genes, BMI1 and c-MYC during early breast tumorigenesis in vitro and in vivo.

\section{Daidzein}

Daidzein (7, 4'-dihydroxyisoflavon), further member of isoflavone family (Atkinsonet al. 2005), consists of two benzene rings, which are linked by pyrone ring (Choi and Kim 2008). Daidzein has been found in soybeans and soy products, in fruits, and in nuts. Daidzein as other flavonoids have an antioxidant activity and they can eliminate reactive oxygen species (ROS), they block generation of ROS and activate an enzymatic antioxidant defense system in vitro. An increasing number of studies suggest that daidzein could be used for chemoprevention or direct treatment of breast cancer (Choi and Kim 2008). Daidzein can inhibit proliferation and induces cell cycle arrest at G0/G1 and G2/M phases through a caspase-3-mediated apoptosis pathway in different cancer cell types (Lo 2013). Choi and Kim (2008) have found that daidzein may also act as a prooxidant. This prooxidant capacity of daidzein as well as its proapoptotic effect could contribute to chemoprevention and to inhibition of tumour growth. Experiments provided by Zhang et al. (2010) showed that daidzein is capable to dilate cerebral basilar artery rings via an endothelium-independent mechanism, which involves the activation of $\mathrm{BK}_{\mathrm{Ca}}$ channels in vascular smooth muscle cells, isolated from rat. Different groups of molecules can activate $\mathrm{BK}_{\mathrm{Ca}}$ channel, like NS1619, 17- $\beta$ estradiol, dehydrosoyasaponin-I, and resveratrol. The $\beta 1$-subunit of these channels plays important role for activation of $\mathrm{BK}_{\mathrm{Ca}}$ currents by daidzein. The estimated binding capacity of daidzein for $\mathrm{ER} \alpha$ and $\mathrm{ER} \beta$ is $100 \mathrm{nM}$ and $420 \mathrm{nM}$, respectively. It 
indicates that daidzein has much lower binding affinity to ER than genistein. At saturating concentrations, daidzein is similarly as genistein capable to interact with ERs, leading to transcriptional activation of ERE at least as effective as the natural ligand for binding of $17 \beta$-estradiol (McCarty 2006). Daidzein induces apoptosis directly without altering the cell cycle distribution. Choi and Kim (2008) clearly showed that daidzein is capable to arrest cell cycle at the G1 and G2/M phases in human breast cancer cells. Furthermore, they have shown that daidzein significantly decreased the proliferation of MCF-7 and MDA-MB-453 cell lines in a dose- and timedependent manner. Sakamoto et al. (2010) investigated supposable candidates for hormone replacement therapy (HRT) and/or chemoprevention of breast cancer by analysing the effects of several kinds of dietary phytoestrogens occurring in soy, soy products, soy supplements, and red clover extract on tumour cell cycle, apoptosis, and cell growth. It appears that daidzein has noantitumour activity in the absence of estradiol and only a partial suppressive effect on estradiolstimulated tumour growth. Although genistein is the most abundant isoflavone in soy and soy products, some supplements have the highest content of daidzein. When examining the estrogenic effect of soy phytoestrogens, it is necessary to consider not only isoflavones and their conjugates in food intake, but also their active metabolites, which may be generated after ingestion in vivo. Daidzein may be converted to equol, the substance possessing much higher estrogenic activity than that of daidzein. Its conversion is probably resulting from gut microflora performance (Muthyala et al. 2004). Another metabolite, that can be produced from daidzein in human and rat liver, is the 7,8,4'-trihydroxyisoflavone (8-hydroxydaidzein; 8HD). This compound exerts multiple biological properties, such as cardioprotective, antioxidative, antiproliferative, radical-scavenging, and tyrosine-inhibitory activities. Tai and his collaborators have shown that $8 \mathrm{HD}$ has depigmentic activities in both mouse melanoma cells (B16) and skin of human volunteers. Thus its potential has been successfully exploited in cosmetic, as skin-whitening ingredients (Tai et al. 2009). Moreover, 8HD was found to have capability to intensify the cytotoxicity of several drugs used in cancer treatment, and thus, it has the ability to reduce doses for chemotherapy, reduce adverse side effects, and subsequently to improve the therapy effect (Lo 2013).

\section{Equol}

Equol [7-hydroxy-3-(49-hydroxyphenyl)-chroman] is a metabolite of the soy isoflavone daidzein. For the first time was equol isolated from mare's urine in 1932. Subsequently, it was found in plasma of sheep. It is likely that it was formed by metabolic conversion from formononetin in red clover (Muthyala et al. 2004). Equol was also discovered in plasma of many other species, including cows, hens, dogs, mice, rats
(Setchell and Clerici 2010), chimpanzees (Blair et al. 2003), monkeys, and pigs ( $\mathrm{Gu}$ et al. 2006). Conversion of the isoflavone daidzein to equol depends on bacterial composition of gut microflora. Typical laboratory animals as rats, mice, and monkeys produce high concentration of equol (Muthyala et al. 2004). It has been shown that gut bacterial modification of soy isoflavones produces metabolites that differ in biological activity from the parent compounds. Among humans, only $30-50 \%$ have the bacteria capable of producing equol and 80-90\% harbor O-desmethylangolensin-producing bacteria (Lampe 2009). In urine, Muthyala et al. (2004) have been reported up to 600-fold variability in equol concentration. Humans, which are capable to metabolize equol from daidzein, have a lower risk of developing of prostate and breast cancer in comparison to non-equol producers. Non-equol producers are those they do not produce equol, even after one month of equol consumption in a day dosage of $34 \mathrm{~g}$. Equol has a stronger estrogenic activity than daidzein and O-desmethylangolensin (O-DMA) (Minamida et al. 2006). It has also been found that equol has much more agonistic effects to ERa in comparison with other isoflavones, genistein and daidzein. Human population is capable of converting daidzein to equol, which activates both estrogen receptors, ERa and ER $\beta$. In a part of population that do not metabolize daidzein to equol this activation occurs predominantly through ER $\beta$ (Ricketts et al. 2005). Ability of metabolic conversion of daidzein to equol can vary in the human population (Matsumura et al. 2005). It depends: i) on above mentioned intestinal microflora activity and stability; ii) on genetic factors influencing the expression of enzymes biotransformation; iii) on impact of environment to gut microflora and enzymes, and iv) on changes in the concentrations of endogenous compounds modulating metabolic pathways (Lampe 2009). Metabolic conversion of daidzein to equol can be affected by ingestion of antibiotics (Atkinson et al. 2004). Enzyme $\beta$-glucosidase takes part in the conversion of daidzin to daidzein. Daidzein is then converted via an intermediate dihydrodaidzein to O-DMA or equol by enzymes of intestinal bacteria. An anaerobic G+ strain HGH 6 converts daidzein to dihydrodaidzein, a Clostridium sp. strain HGH 136 and Eubacterium ramulus converts daidzein to O-DMA. SNU Julong, human intestinal bacteria, converts dihydrodaidzein to equol. A mixture of Bacteroides ovatus, Ruminococcus productus and Streptococcus intermedius or Lactobacillus mucosae, Enterococcus faecium, Finegoldiamagna and Veillonella sp. produces equol from daidzein (Minamida et al. 2006). In general, intestinal microflora thus plays an important role in daidzein conversion. Therefore, children with under-developed intestine are not capable to produce equol or O-DMA. The estimated bacterial pattern in human colon represents more than 400 bacterial species (Atkinson et al. 2005).

Chemically, equol has heterocyclic structure contains two reactive hydroxyls and one unreactive oxygen, which 
arelocated in the central furan ring. Physicochemically, it is a nonpolar compound, relatively insoluble in water. It is also extremely acid-labile and can readily be destroyed (Setchell and Clerici 2010). Equol is a chiral molecule; it can exist in two enantiomeric forms. The enantiomer, produced by metabolic reduction from isoflavones, is known as $\mathrm{S}(-)$ equol, and synthetic preparation is predominantly $\mathrm{R}(+)$ equol. Bacteria are enantioselective in metabolizing daidzein to exclusively $\mathrm{S}(-)$ equol and not $\mathrm{R}(+)$ equol. Synthetically prepared equol has been shown to induce proliferation of breast cancer cells in culture at concentration as low as $100 \mathrm{nM}$. Biological properties both of enantiomers investigated by Muthyala et al. (2004) have shown different effects of these enantiomers in relation to binding affinity and transcription activity to both ERa and ER $\beta$.S-equol has a preference for ER $\beta$ and R-equol for ERa (Muthyala et al. 2004; Setchell and Clerici 2010). Magge's team has shown that R- and S-equol inhibit the invasion of MDAMB-231 cell line in part via the down-regulation of matrix metalloproteinase-2 (MMP-2) expression. The identical effect was also observed for daidzein (Magee et al. 2013).

\section{Formononetin}

Formononetin [7-hydroxy-3(4-methoxypheny)chromone], an O-methylated isoflavone, is a major compound of the root of Astragalus membranaceus (Wu et al. 2010). This medicinal herb has been used in oriental medicine to improve insufficient of blood microcirculation, and for the treatment of blood circulation stasis (Huh et al. 2011). Further, formononetin was discovered in Trifolium platense (red clover) and in large amounts it is present in vegetables, seeds, and fruits ( $\mathrm{Li}$ et al. 2006; Wu et al. 2010). Extract from T. platense is used for the treatment of cardiovascular diseases (Wu et al. 2010). The concentration of formononetin in plant species varies a lot with the highest concentrations being in leaves and the lowest in flowers (Mu et al. 2009). Currently, formononetin is isolated from herbs and its activity is standardized to therapeutic application in medical research (Huh et al. 2011). It has been shown that formononetin effectively inhibits IL- $1 \beta$-induced apoptosis in INS-1 cells (rat insulin-secreting cell line) and also decreases expression of proteins in IL- $1 \beta$-mediated apoptotic pathway. Activation of NF- $\mathrm{kB}$ is identical with the expression of the proinflammatory marker iNOS. Therefore NF- $\mathrm{kB}$ would be a candidate target for new anti-inflammatory and anti-apoptosis treatment. Formononetin is known to block IL- $1 \beta$-induced NF- $\kappa B$ activation and reduce NF- $\kappa B$ complex translocation from the cytoplasm to nucleus (Wang et al. 2012). In addition, formononetin possesses hypolipidemic properties, estrogenic and antioxidative effects. Formononetin exerts endothelium-/NO-dependent and endothelium-independent relaxation effects. The endothelium-independent part of relaxation inducing by formononetin is associated with the activation of both $\mathrm{K}_{\mathrm{ATP}}$ and $\mathrm{BK}_{\mathrm{Ca}}$ channels of the vascular tissues. Intake of formononetin could have some beneficial effects on the cardiovascular system in postmenopausal women (Wu et al. 2010). On the other hand, it supports early bone fracture healing by stimulating angiogenesis enhancing VEGF (vascular endothelial growth factor) and VEGFR-2 expression yielding in induction of osteogenesis in fractured rat (Huh et al. 2009). Formononetin causes cell cycle arrest at the G0/G1 phase by inactivating IGF1/IGF1R-PI3K/Akt pathways and decreasing cyclin D1mRNA and protein expression, indicating the use of formononetin in the prevention of breast cancer carcinogenesis (Chen et al. 2011).

\section{Biochanin A}

Biochanin A (4'-methoxygenistein) is derivate of genistein and major isoflavone of chick pea (Dixon and Ferreira 2002); it is also present in cabbage, red clover, and alfalfa (Medicago sativa, also called lucerne) (Kole et al. 2011). Its estrogenic activity is lower in comparison with other structurally similar isoflavones. It can be easily converted to genistein by the intestinal microflora and by liver CYP450 isoenzymes (Lapcík et al. 2004). It has a protective effect on chemically induced carcinogenesis in stomach, blood, bladder, lung, and prostate. Inhibition effect on growth of human stomach cancer cell lines in vitro by biochanin A and his precursor genistein probably stimulates signal transduction pathways what can lead to apoptosis (Dixon and Ferreira 2002). Biochanin A potentiates cytostatic activity of doxorubicin by a P-glycoprotein-mediated mechanism. It is a weak antioxidant, and its radical scavenging activity is very low. On the other hand, biochanin A is capable to modify several types of oxydoreduktase enzymes, which belong to the steroid metabolism and it inhibits effect of xenobiotics, including benzopyrene-A (Lapčík et al. 2004). Both isoflavones genistein and biochanin $A$ have similar effects on bone metabolism. However, biochanin A is selective isoflavone for $\mathrm{ER} \beta$, and it stimulates differentiation and mineralization of osteoblasts, while osteoclast differentiation and bone resorption were found to be suppressed by biochanin A (Su et al. 2013). Biochanin A is also an important prevention factor of phosphorylation and degradation I $\mathrm{KB} \alpha$ (nuclear factor of kappa light polypeptide gene enhancer in B-cells inhibitor, alpha), thereby blocking NFKB activation and nuclear translocation, what leads to decreasing transcription of the iNOS and other pro-inflammatory genes (Kole et al. 2011).

In our laboratory, we have investigated influence of different concentration of isoflavones daidzein and genistein alone/or in combination with vitamin $\mathrm{D}_{3}$ ligands (vitamin $\mathrm{D}$ and seocalcitol) on the expression of selected nuclear receptors. We have found increased/decreased selected nuclear receptor subtypes expression, after cells treatment with the compounds alone or in their combination. Furthermore, we have found changes in expression of 1-alpha hydroxylase and 24-hydroxylase, which 
are key enzymes participating on the vitamin D metabolism. In comparison with mock untreated control group, we have found changes in nuclear receptor coregulators (SMRT-Silencing Mediator of Retinoic Acid and Thyroid Hormone Receptor, SRC-Steroid Receptor Coactivator, NCoR-Nuclear Receptor Corepresor) expression after in vitro treatment of human breast cancer cells with isoflavones daidzein and genistein alone/or in combination with vitamin $\mathrm{D}_{3}$ ligands (Bialešová et al. 2012). Further work with isoflavones- biologically active compounds and also nuclear targets, is warranted.

Acknowledgements. This work was supported by APVV-0160-11, VEGA 2/0008/11, APVV-SK-CZ-0211-11, 7AMB12SK151and CEMAN grants.

\section{References}

Adlercreutz H. (2003): Phytoestrogens and breast cancer. J. Steroid Biochem. Mol. Biol. 83, 113-118 http://dx.doi.org/10.1016/S0960-0760(02)00273-X

Andres A., Donovan S. M., Kuhlenschmidth M. S. (2009): Soy isoflavones and virus infections. J. Nutr. Biochem. 20, 563-569 http://dx.doi.org/10.1016/j.jnutbio.2009.04.004

Ascenzi P., Bocedi A., Marino M. (2006): Structure-function relationship of estrogen receptor alpha and beta: impact on human health. Mol. Aspects Med. 27, 299-402 http://dx.doi.org/10.1016/j.mam.2006.07.001

Atkinson C., Berman S., Humbert O., Lampe J. W. (2004): In vitro incubation of human feces with daidzein and antibiotics suggests interindividual differences in the bacteria responsible for equol production. J. Nutr. 134, 596-599

Atkinson C., Frankenfeld C., Lampe J. (2005): Gut bacterial metabolism of the soy isoflavone daidzein: exploring the relevance to human health. Exp. Biol. Med. 230, 155-170

Bella V. (2009): Hereditary forms of breast cancer. Onkológia 4, 76-79 (in Slovak)

Bella V., Kállayová A. (2011): The national screening program for breast cancer of the Slovak Republic (comprehensive proposal). (in Slovak)

Bialešová L., Macejová D., Brtko J. (2012): Genistein in combination with vitamin D3 receptor ligands affects expression of selected nuclear receptors. Abstracts from the International Alumni Symphosium: „Bioactive principles of medicinal plants and diet“, Dresden, Germany, 21

Blair R. M., Appt S. E., Franke A. A., Clarkson T. B. (2003): Treatment with antibiotics reduces plasma equol concentration in cynomolgus monkeys (Macaca fascicularis). J. Nutr. 133, 2262-2267

Brtko J. (2007): Retinoids, rexinoids and their cognate nuclear receptors: character and their role in chemoprevention of selected malignant diseases. Biomed. Pap. Med. Fac. Univ. Palacky Olomouc Czech Repub. 151, 187-194 http://dx.doi.org/10.5507/bp.2007.033

Brtko J., Dvořák Z. (2011): Role of retinoids, rexinoids and thyroid hormone in the expression of cytochrome p450 enzyme. Curr. Drug Metab. 12, 1-17

http://dx.doi.org/10.2174/138920011795016881
Callero M. A., Loaiza-Pérez A. I. (2011): The role of aryl hydrocarbon receptor and crosstalk with estrogen receptor in response of breast cancer cells to the novel antitumor agents benzothiazoles and aminoflavone. Int. J. Breast Cancer, 923250

Davis D. D, Días-Cruz E., Landini S., Kim Y. W., Brueggemeier R. W. (2008): Evaluation of synthetic isoflavones on cell proliferation, estrogen receptor binding affinity, and apoptosis in human breast cancer cells. J. Steroid Biochem. Mol. Biol. 108, 23-31 http://dx.doi.org/10.1016/j.jsbmb.2007.07.001

Dixon R., Ferreira D. (2002): Genistein. Phytochemistry 60, 205-211 http://dx.doi.org/10.1016/S0031-9422(02)00116-4

Gu, L., House S. E., Prior R. L., Fang N., Ronis M. J. J., Clarkson T. B., Wilson M. E. Badger T. M. (2006): metabolic phenotype of isoflavones differ among female rats, pigs, monkeys, and women. J. Nutr. 136, 1215-1221

Gustafsson J. (2000): An update on estrogen receptors. Semin. Perinatol. 24, 66-69 http://dx.doi.org/10.1016/S0146-0005(00)80059-2

Heinonena S-M., Hoikkalab A., Wähäläb K., Adlercreutz H. (2003): Metabolism of the soy isoflavones daidzein, genistein and glycitein in human subjects. Identification of new metabolites having an intact isoflavonoid skeleton. J. Steroid Biochem. Mol. Biol. 87, 285-299 http://dx.doi.org/10.1016/j.jsbmb.2003.09.003

Hilakivi-Clarke L., Cabanes A., Olivo S., Kerr L., Bouker K. B., Clarke R. (2002): Do estrogens always increase breast cancer risk? J. Steroid Biochem. Mol. Biol. 80, 163-174 http://dx.doi.org/10.1016/S0960-0760(01)00184-4

Hillman G. G., Singh-Gupta V. (2011): Soy isoflavones sensitize cancer cells to radiotherapy. Free Radic. Biol. Med. 51, 289-298 http://dx.doi.org/10.1016/j.freeradbiomed.2011.04.039

Huh J-E., Nam D-W., Baek Y-H., Kang J-W., Park D-S., Choi D-Y., Lee J-D. (2011): Formononetin accelerates wound repair by the regulation of early growth response factor-1 transcription factor through the phosphorylation of the ERK and p38 MAPK pathways. Int. Immunopharmacol. 11, 46-54 http://dx.doi.org/10.1016/j.intimp.2010.10.003

Chen J., Zeng J., Xin M., Huang W., Chen X. (2011): Formononetin induces cell cycle arrest of human breast cancer cells via IGF1/PI3K/Akt pathways in vitro and in vivo. Horm. Metab. Res. 43, 681-686 http://dx.doi.org/10.1055/s-0031-1286306

Choi E. J., Kim G. H. (2008): Daidzein causes cell cykle arrest at the G1 and G2/M phases in human breast cancer MCF-7 and MDA-MB-453 cells. Phytomedicine 15, 683-690 http://dx.doi.org/10.1016/j.phymed.2008.04.006

Im J-Y., Park H., Kang K. W., Choi W. S., Kim H. S. (2008). Modulation of cell cycles and apoptosis by apicidin in estrogen receptor (ER)-positive and-negative human breast cancer cells. Chem. Biol. Interact. 172, 235-244 http://dx.doi.org/10.1016/j.cbi.2008.01.007

Imhof M., Molzer S., Imhof M. (2008): Effects of soy isoflavones on 17b-estradiol-induced proliferation of MCF-7 breast cancer cells. Toxicol in Vitro 22, 1452-1460 http://dx.doi.org/10.1016/j.tiv.2008.04.018

Jin L., Li Y. (2010): Structural and functional insights into nuclear receptor signaling. Adv. Drug Deliv. Rev. 62, 1218-1226 
http://dx.doi.org/10.1016/j.addr.2010.08.007

Kang X., Zhang Q., Wang S., Huang X., Jin S. (2010): Effect of soy isoflavones on breast cancer recurrence and death for patients receiving adjuvant endocrine therapy. CMAJ 182, 1857-1862 http://dx.doi.org/10.1503/cmaj.091298

Kharat I., Saatcioglu F. (1996): Antiestrogenic effects of 2,3,7,8tetrachlorodibenzo-p-dioxin are mediated by direct transcriptional interference with the liganded estrogen receptor. Cross-talk between aryl hydrocarbon- and estrogen-mediated signaling. J. Biol. Chem. 271, 10533-10537 http://dx.doi.org/10.1074/jbc.271.18.10533

Kole L., Giri B., Manna S. K., Pal B., Ghosh S. (2011): Biochanin-A, an isoflavon, showed anti-proliferative and anti-inflammatory activities through the inhibition of iNOS expression, p38MAPK and ATF-2 phosphorylation and blocking NFKB nuclear translocation. Eur. J. Pharmacol. 653, 8-15 http://dx.doi.org/10.1016/j.ejphar.2010.11.026

Lampe J. (2009): Is equol the key to the efficacy of soy foods? Am. J. Clin. Nutr. 89, 1664-1667 http://dx.doi.org/10.3945/ajcn.2009.26736T

Lapčík O., Vítková M., Klejdus B., Al-Maharik N., Adlercreutz H. (2004): Immunoassay for biochanin A. J. Immunol. Methods 294, 155-163 http://dx.doi.org/10.1016/j.jim.2004.09.004

Lazennec G., Bresson G., Lucas A., Chauveau C., Vignon F. (2001): ER beta inhibits proliferation and invasion of breast cancer cells. Endocrinology 142, 4120-4130 http://dx.doi.org/10.1210/en.142.9.4120

Lee Y-B., Lee H. J., Sohn H. S.(2005): Soy isoflavones and cognitive function. J. Nutr. Biochem. 16, 641-649 http://dx.doi.org/10.1016/j.jnutbio.2005.06.010

Li C. I., Uribe D. J., Daling R. J. (2005): Clinical characteristics of different histologic types of breast cancer. Br. J. Cancer 93, 1046-1052 http://dx.doi.org/10.1038/sj.bjc.6602787

Li Y., He W. Y., Dong Y. M., Sheng F., Hu Z. D. (2006): Human serum albumin interaction with formononetin studied using fluorescence anisotropy, FT-IR spectroscopy, and molecular modeling methods. Bioorg. Med. Chem. 14, 1431-1436 http://dx.doi.org/10.1016/j.bmc.2005.09.066

Li Y., Chen H., Hardy T. M., Tollefsbol T. O. (2013): epigenetic regulation of multiple tumor-related genes leads to suppression of breast tumorigenesis by dietary genistein. PLoS One 8, 1-12

Liggins J., Bluck L. J. C., Runswick S., Atkinson Ch., Coward W. A., Bingham S. A. (2000): Daidzein and genistein content of fruits and nuts. J. Nutr. Biochem. 11, 326-331 http://dx.doi.org/10.1016/S0955-2863(00)00085-1

Lo Y. L. (2013): A Potential Daidzein Derivative Enhances Cytotoxicity of Epirubicin on Human Colon Adenocarcinoma Caco-2 Cells. Int. J. Mol. Sci. 14, 158-176 http://dx.doi.org/10.3390/ijms14010158

Luthria D. L., Biswas R., Natarajan S. (2007): Comparison of extraction solvents and techniques used for the assay of isoflavones from soybean. Food Chemistry 105, 325-333 http://dx.doi.org/10.1016/j.foodchem.2006.11.047

McCarty M. (2006): Isoflavones made simple - genisteins agonist activity for the beta-type estrogen receptor mediates their health benefits. Med. Hypotheses 66, 1093-1114 http://dx.doi.org/10.1016/j.mehy.2004.11.046

Magee P. J., McGlynn H., Rowland R. I. (2004): Differential effects of isoflavones and lignans on invasiveness of MDA-MB-231 breast cancer cells in vitro. Cancer Lett. 208, 35-41 http://dx.doi.org/10.1016/j.canlet.2003.11.012

Magee P. J., Allsopp P., Samaletdin A., Rowland I. R. (2013): Daidzein, R-(+)equol and S-(-)equol inhibit the invasion of MDAMB-231 breast cancer cells potentially via the down-regulation of matrix metalloproteinase-2. Eur. J. Nutr. (in press) http://dx.doi.org/10.1007/s00394-013-0520-z

Mangelsdorf D. J., Thummel C., Beato M., Herrlich P., Schütz G., Umesono K., Blumberg B., Kastner P., Mark M. (1995): The nuclear receptor superfamily: the second decade. Cell 83, 835-839 http://dx.doi.org/10.1016/0092-8674(95)90199-X

Matsumura A., Ghosh A., Pope G. S., Darbre P. D. (2005): Comparative study of oestrogenic properties of eight phytoestrogens in MCF7 human breast cancer cells. J. Steroid Biochem. Mol. Biol. 94, 431-443 http://dx.doi.org/10.1016/j.jsbmb.2004.12.041

Medjakovic S., Mueller M., Jungbauer A. (2010): Potential healthmodulating effects of isoflavones and metabolites via activation of PPAR and AhR. Nutrients 2, 241-279 http://dx.doi.org/10.3390/nu2030241

Messina M., Wu A. H. (2009): Perspectives on the soy-breast cancer relation. Am. J. Clin. Nutr. 89, 1673-1679 http://dx.doi.org/10.3945/ajcn.2009.26736V

Minamida K., Tanaka M., Abe A., Sone T., Tomita F., Hara H., Asano K. (2006): Production of equol from daidzein by grampositive rod-shaped bacterium isolated from rat intestine. J. Biosci. Bioeng. 102, 247-250 http://dx.doi.org/10.1263/jbb.102.247

Mu H., Bai Y.-H., Wang S.-T., Zhu Z.-M., Zhang Y.-W. (2009): Research on antioxidant effects and estrogenic effects of formononetin from Trifolium pratense (Red clover). Phytomedicine 16, 314-319 http://dx.doi.org/10.1016/j.phymed.2008.07.005

Mustacchi G., Cazzaniga M. E., Pronzato P., Matteis A. De., Costanzo F. Di., Floriani I. (2007): Breast cancer in elderly women: a different reality? Results from the NORA study. Ann. Oncol. 18, 991-996 http://dx.doi.org/10.1093/annonc/mdm063

Muthyala R. S., Ju Y. H., Sheng S., Williams L. D., Doerge D. R., Katzenellenbogen B. S., Helferichb W. G., Katzenellenbogen J. A. (2004): Equol, a natural estrogenic metabolite from soy isoflavones: convenient preparation and resolution of R- and S-equols and their differing binding and biological activity through estrogen receptors alpha and beta. Bioorg. Med. Chem. 12, 1559-1567 http://dx.doi.org/10.1016/j.bmc.2003.11.035

Nikolenko J. V., Krasnov A. N. (2007): Nuclear receptors: structure and mechanisms of action. Genetika 43, 234-240

Okoh V., Deoraj A., Roy D. (2011): Estrogen-induced reactive oxygen species-mediated signalings contribute to breast cancer. Biochim. Biophys. Acta 1815, 115-133

Ondrušová M. (2009): Epidemiology of breast cancer. Onkológia 4, 72-75 (in Slovak)

Pavese J. M., Farmer R. L., Bergan R. C. (2010): Inhibition of cancer cell invasion and metastasis by genistein. Cancer Metastasis Rev. 29, 465-482 
http://dx.doi.org/10.1007/s10555-010-9238-z

Pearce S. T., Jordan V. C. (2004): The biological role of estrogen receptors $\alpha$ and $\beta$ in cancer. Crit. Rev. Oncol. Hematol. 50, $3-22$

http://dx.doi.org/10.1016/j.critrevonc.2003.09.003

Platet N., Cathiard A. M., Gleizes M., Garcia M. (2004): Estrogens and their receptors in breast cancer progression: a dual role in cancer proliferation and invasion. Crit. Rev. Oncol. Hematol. 51, 55-67 http://dx.doi.org/10.1016/j.critrevonc.2004.02.001

Rice S., Whitehead S. A. (2003): Phytoestrogens oestrogen synthesis and breast cancer. J. Steroid Biochem. Mol. Biol. 108, 186-195 http://dx.doi.org/10.1016/j.jsbmb.2007.09.003

Rice S., Whitehead S. (2006): Phytoestrogens and breast cancer-promoters or protectors?. Endocr. Relat. Cancer 13, 995-1015 http://dx.doi.org/10.1677/erc.1.01159

Rice S., Whitehead S. (2008): Phytoestrogens oestrogen synthesis and breast cancer. J. Steroid Biochem. Mol. Biol. 108, $186-195$ http://dx.doi.org/10.1016/j.jsbmb.2007.09.003

Ricketts M-L., Moore D. D., Banz W. J., Mezei O., Shay N. F. (2005): Molecular mechanisms of action of the soy isoflavones includes activation of promiscuous nuclear receptors. J. Nutr. Biochem. $16,321-330$ http://dx.doi.org/10.1016/j.jnutbio.2004.11.008

Safe S., Wang F., Porter W., Duan R., McDougal A. (1998): Ah receptor agonists as endocrine disruptors: Antiestrogenic activity and mechanism. Toxicol. Lett. 343, 102-103

Sakamoto T., Horiguchi H., Oguma E., Kayama F. (2010): Effects of diverse dietary phytoestrogens on cell growth, cell cycle and apoptosis in estrogen-receptor-positive breast cancer cells. J. Nutr. Biochem. 21, 856-864 http://dx.doi.org/10.1016/j.jnutbio.2009.06.010

Satih S., Chalabi N., Rabiau N., Bosviel R., Fontana L., Bignon Y-J., Bernard-Gallon D. J. (2010): Gene expression profiling of breast cancer cell lines in response to soy isoflavones using a pangenomic microarray approach. Omics 14, 231-238 http://dx.doi.org/10.1089/omi.2009.0124

Setchell K., Clerici C. (2010): Equol : history, chemistry, and formation. J. Nutr. 3, 1355-1362 http://dx.doi.org/10.3945/jn.109.119776

Shukla S., MacLennan G. T., Pingfu F., Patel J., Marengo S. R., Resnick M. I., Gupta S. (2004): Nuclear Factor-nB/p65 (Rel A) is constitutively activated in human prostate adenocarcinoma and correlates with disease progression. Neoplasia 6, 390-400 http://dx.doi.org/10.1593/neo.04112
Su S-J., Yeh Y-T., Shyu H-W. (2013): The preventive effect of biochanin A on bone loss in ovariectomized rats: involvement in regulation of growth and activity of osteoblasts and osteoclasts. Evid. Based Complement Alternat. Med. 594857

Suva L.-J., Griffin R.-J., Makhoul I. (2009): Mechanisms of bone metastases of breast cancer. Endocr. Relat. Cancer 16, 703-713 http://dx.doi.org/10.1677/ERC-09-0012

Tai S. S-K., Lin Ch-G., Wu M. H., Chang T-S. (2009): evaluation of depigmenting activity by 8 -hydroxydaidzein in mouse b16 melanoma cells and human volunteers. Int. J. Mol. Sci. 10, 4257-4266 http://dx.doi.org/10.3390/ijms10104257

This P., Cremoux P., Leclercq G., Jacquot Y. (2011): A critical view of the effects of phytoestrogens on hot flashes and breast cancer risk. Maturitas 70, 222-226 http://dx.doi.org/10.1016/j.maturitas.2011.07.001

Trifiletti A., Gaudio A., Lasco A., Atteritano M., Scamardi R., Pizzoleo M. A, Morabito N., Frisina N.(2008): Haemostatic effects of phytoestrogen genistein in postmenopausal women. Thromb. Res. 123, 231-235 http://dx.doi.org/10.1016/j.thromres.2008.02.009

Wang Y., Zhu Y., Gao L., Yin H., Xie Z., Wang D., Zhu Z., Han X. (2012): Formononetin attenuates IL-1 $\beta$-induced apoptosis and NF- $\kappa B$ activation in INS- 1 cells. Molecules 17, 10052-10064 http://dx.doi.org/10.3390/molecules170910052

Wu J-H., Li Q., Wu M-Y-, Guo D-J., Chen H-L., Chen S-L., Seto S-W., Au A. L. S., Poon Ch. C.W., Leung G.P.H., Lee S. M.Y., Kwan YW., Chan S-W. (2010): Formononetin, an isoflavone, relaxes rat isolated aorta through endotelium-dependent and endoteliumindependent pathways. J. Nutr. Biochem. 21, 613-620 http://dx.doi.org/10.1016/j.jnutbio.2009.03.010

Wuttke W., Hubertus J., Seidlová-Wuttke D. (2007): IsoflavonessSafe food additives or dangerous drugs? Ageing Res. Rev. 6, $150-188$ http://dx.doi.org/10.1016/j.arr.2007.05.001

Wood Ch. E., Register C. T., Cline J. M. (2007): Soy isoflavonoid effects on endogenous estrogen metabolism in postmenopausal female monkeys. Carcinogenesis 28, 801-808 http://dx.doi.org/10.1093/carcin/bgl163

Zhang T-H., Wang Y., Deng Y-L., Dong M-Q., Zhao L-M., Wang Y-W. (2010): Daidzein relaxes rat cerebral basilar artery via activation of large-conductance $\mathrm{Ca} 2+$-activated $\mathrm{K}+$ channels in vascular smooth muscle cells. Eur. J. Pharmacol. 1-3, 100-106 http://dx.doi.org/10.1016/j.ejphar.2009.12.032

Received: May 30, 2013

Final version accepted: July 31, 2013 